\title{
Regional and International Market - Adventure or Possibility to Develop Faster
}

\author{
llir Bejtja \\ Economic Faculty, University "Aleksander Xhuvania" Elbasan, Albania
}

Azeta Tartaraj

Faculty of Business, University "Aleksandër Moisiu" Durres, Albania

\section{Doi:10.5901/mjss.2014.v5n27p1774}

\begin{abstract}
Albania is now facing international competition since the officially establishment of the market economy, based on the free competition and economic diversity in every sector. It lived a rapid opening toward international market on the very early stage of this new era and the establishment of democracy model of state. The huge differences in development, education, perception and experience induced rapidly a system of market exchange deeply in favor of imports in front of exports. Even several steps, important ones, done on the improvement of the balance projecting and designing a market development law reform, as well as policies fostering domestic market development and the stimulation of exports versus imports, still our economy lacks a lot in this matter. Most of the policies and steps done to this issue aimed at the protectionist actions through tax barriers in order to preserve, not to develop the actual inherited economy, or that very decadent installed industry lacking considerably innovation and advanced technology. The accession to WTO, the several multilateral agreements, regional and international, Albania signed and participates, as well as the bilateral agreement with EU on the free trade for the genuine products and the signature of SAA and the process of EU integration, made it impossible that Albania could face international market exchanges with that very latent philosophy and approach on development of the very first years of market economy, and the situation on imports and exports has deepen the advantage of the first versus the second. At this stage, the question stands rather we could be part of this market being leader in innovation and technology, or instead, internationalizing our brands and products increasing quality, respecting international standards on this regard and emphasizing their Albanian origin as a new gusto and another possibility in the international market for the costumer, considering international channels of marketing cost reduction too? So, principally the question stands if we can and how to develop an economic model producing products and services fitting international and regional market standards in quality and consumption, as well as easily identifiable to the international customer?
\end{abstract}

Keywords: International market, standards of quality, genuine products and brands, made in Albania.

\section{Introduction}

If we take a look on the recent years in the Albania's economic development, and consider in the meantime the worldwide crisis, especially the European situation, we can still think of some healthy economy struggling to guarantee a stable growth year by year. The figures of the last five years show instead a strong falling acceleration rhythm of growth:

\begin{tabular}{|c|c|c|c|c|c|c|}
\hline & 2007 & 2008 & 2009 & 2010 & 2011 & 2012 \\
\hline GDP Growth (\%) & 5.9 & 7.5 & 3.3 & 3.91 & $3.1 \% 1$ & NA $^{2}$ \\
\hline
\end{tabular}

If we calculate the falling acceleration rhythm it has a steady negative trend of more than $20 \%$ each year. At least for the Albanian business and financial system this is a very critical situation and warning too. Other figures of the last year show for an economy which has already consumed all the possible cost/price options and factors, in order to ensure further increase and growth for the Albanian economy. Figures show that we still have a predominance of productivity in GDP by the services sector (more than 59\%) and the two other sectors divided $21 \%$ agriculture, $20 \%$ industry shared in $8 \%$

\footnotetext{
${ }^{1}$ Report of monetary policy on the first trimester 2012, Bank of Albania, pp. 27

2 "The indirect quantitative and qualitative data, as well as the estimations and prognosis on the developments in the country and worldwide suggest that the economic growth on the first trimester 2012 as been slow in the same trend with its historical behavior." Bank of Albania 2012
} 
manufacturing and $12 \%$ production sector. Even this distribution, the level of mechanization and automatization of the productive activities remain decadent and low. We have a low capital structure in all the sectors above compared to the regional and EU industry. We still do not perform high yields of production having relatively high cost of production compared to the price index of production. Our competitiveness based on costs and economy of scale seems to be now an impossible enterprise. We are weakly attractive considering cost factors and the prices too in the domestic and international market. This is shown too by the deepening of the trade deficit at the end of 2011 and the first two months of $2012^{3}$.

The high level of financial leverage in the Albanian companies, the large weight the debts share on the assets they use on long terms (many cases more than the half), and the often very negative cash flow during the year call for attention to our companies and to the government too. The high level of the problematic loan/credit for the banks of the second level, almost $21 \%$ declared on the early four months of 2012, the increase in unemployment with more than $10 \%$ compared to 2010 and the deepening of the phenomenon on the first four months of 2012, the continuous negative growth in consumption mounting more than "-18\%" on the first four months of 2012 compared to the same period on $2011^{4}$, show for hard times even on the near future, fall 2012 and the upcoming year 2013. The still weak weight of export in the trade balance and the still strongly in favor of import on 2011 and the first two months of 2012, show for a low competitive power of Albanian economy in the international market and in the same time e strongly negative trade balance of payments. The fall in remittances on 2011 with almost $11 \%$ compared to 2009 and their trend to diminish further in the future, considering also the hard situation of our immigrant community in the countries they live and work show for another cutting of the cost/price options and factors fostering the future growth of the Albanian economy.

At this situation the question rises on which other factors to use in order to ensure a steady growth of the Albanian economy? The non price factors, of course, are a very important tool to foster this growth and the Albanian economic development. If we analyze the Albanian products and services state of nature, we can easily identify several non price factors/variables having a strong correlation and impact on the future development of our economy and of its growth. We can concentrate on standardization of the products and services too, considering the control of origin, process of production, branding, promotion, marketing channels in order to increase the internationalization of our products and services regionally and more, and in the same time to improve the trade balance reducing trade deficit, giving breath to our suffering economy of the last three years.

\subsection{Main Research Question:}

How should we develop domestic economy in the light of regional and international market?

\section{Literature Review}

Going international is a huge challenge in any case for all businesses. It is not just a strategic matter, but a matter of international commitments to be fulfilled too. If we see startup companies recently worldwide regarding mission statement and strategic goals definition, most of those mention and aim internationalization as key step in their future success. The same change in philosophy has occurred recently even in the traditional old domestic orientation businesses too. Internationalization and globalization are now not just familiar words and concepts in economy and throughout the enterprises worldwide, but necessities to be considered, strongly related to their actual and future existence. What does it mean going international? What does it mean international and global products and brands? Are these concepts the same to all the businesses worldwide? Are these concepts of the same meaning to all the businesses independently by the size of the company? Furthermore, what makes a product or service, or brand an international one? On this regard, we can chose different ways of being international; product or brand oriented, company or home nation oriented, process oriented, as well as operations oriented. All these orientations, however, seem to have one common thing, international standards and characteristics answering to international market demand.

While many authors refer to business activities of the transnational firms, as well as transnational transactions and to the advantages of international perspective compared to the domestic ones, on an international perspective this is not always considered an advantage even to micro and small firms. They suffer struggling against this recent consolidated trend already operating in their home market, considering their relatively weakly rigorous behavior to respect consumption and process standards imposed by the international competition with their products and services, as well as the rules of

\footnotetext{
${ }^{3}$ Report of monetary policy on the first trimester 2012, Bank of Albania

${ }^{4}$ Bank of Albania 2012
} 
operation and strictly binding norms of consumption due to health and nutrition, and quality principles stated often through official international covenants. This harsh competition has induced those to international thinking on their success. This is related to the fact that the domestic market is not anymore too rich in chances and perspectives, because the "free spaces to home tradition consumption base" firms do not exist any longer. The consumer has changed toward global gusto. The international firms are each day more intensively present and aggressive in the market, targeting new markets to sustain their success. Internationalization is now "as serious threat" for the deeply domestic oriented enterprises. Ulterior reasons on the internationalization are also the international economic and political institutions fostering international exchange and market development. They strongly foster a new barrier-less business environment, a multidimensional market development implying cultural diversity and consumption too.

Does international marketing imply other principles or rules to internationalize? Generally the answer is 'no'. Principles of establishing business and marketing objectives, on the choice of the target market, on the positioning development and on the marketing mix, as well as on the application of the marketing control apply in international marketing to $0^{5}$. There are no new principles. The difference stands on the international market dimensions, not just size, but differences deriving from the diversity of the countries comprised in the international market in several aspects as culture, economy, politics and law, territory, size, technology and innovation etc.

So once again, what does it mean going international? It just means planning and doing transactions of your business beyond the national borders ${ }^{6}$. It implies several forms from export to joint-ventures and FDI, as well as strategic alliances and integrated marketing channels managing international products, services, brands and processes under international or global standards. Due to out of border activities the international business manager is subject to a set of factors and limitations deriving from the international macro-environment related to political systems, law frameworks, culture and economic situations functioning differently compared to domestic markets.

It seems pretty hard to internationalize. Then, it naturally rises the question; Why going international? The answer is already demystified now in different cases and the situation described in the introduction here regarding Albanian economy certifies the necessity on moving international. It is not a per se goal, neither an escape from difficulties which are hard to resolve due to impossibility in the domestic market, but it is rather more an approach guaranteeing continuity and space to growth, as well as endless maximization of our business and profits. It is also a question of competition, facing it everywhere, in the domestic market but more, internationally as more spaces are available and more tools can comprise our business mix.

But, as we arouse the question here above, it implies international standards too. These ensure that products and services are safe, reliable and of a certified quality, as well as guarantee procedures and processes to be followed under certified rules of behavior. They reduce costs minimizing waste and errors referring to certified experiences and increasing productivity under rigorous technology use. They help companies to enter new markets and define the ways to move toward development to developing economies under respect of rules and international laws accepted internationally by global and international institutions? ${ }^{7}$. They provide tools for tackling many global challenges today in the international market. The integration of the domestic markets to international ones, as well as to the global one, have induced the standardization of these too, moving and developing under certain standards often obligatory to be implemented. Another approach is that these standards are developed by international organizations and induced to be binding under membership and signature (EU standards). The rules and standards at this approach can be respected directly at the production process or in the undertaken of modification processes to existing products and services. These are standards to overcome technical and national barriers to make possible international commerce and marketing. Terms comprising the international standards are several; international consumer, international integrated marketing communication, packaging and promotion, international trade rules, health and food security and hygiene, quality, size, content, language, culture etc. ${ }^{8}$

By operational view, especially in marketing actions, as this imply involvement of the customer too and as the marketing people are led by the principle that the only standard in marketing is fantasy and lack of standard, with the goal "trying to fit the next prospective customer", international standards have transformed it in a set of actions and principles respecting international customer values based on the statement "think globally and act locally". As for the sector of

\footnotetext{
${ }^{5}$ International Marketing: An SME Perspective, Sean De Burca, Linden Brown and Richard Fletcher, Financial Times/ Prentice Hall; 1 edition 2004

${ }^{6}$ Czinkota \& Ronkainen 2004, International Marketing, pp 4.

7 ISO definition on standards

${ }^{8}$ British American Tobacco Marketing Standards, November 2011

9 Marketing Management, Kotler and Keller, 12e, 2006, pp. 154-155
} 
marketing it implies professional marketing standards, a practical framework of marketing abilities which provides a guide to the skills that are expected by the marketing professionals at varying levels of seniority ${ }^{10}$. The requests on these regard are comprised in a set of KPI (Key Performance Indicators) and other marketing metrics too, involving process, customer care, security, organization, records, product design and style, compliance care, ethical and social responsibility and application of several covenants protecting customers and businesses from the marketing's aggressive character.

International standards imply also for international marketing business and channels. They standardize relationships between businesses, records and supervision, logistics, flows and their movement through the channels, hierarchy conflict resolution in the channel, costs and prices, margins and rights, capital and financial issues, risk management, business conduct standards, "...committed to reforms in the over-the-counter ("OTC") derivatives market to improve transparency, mitigate systemic risk, and protect against market abuse, ... by providing high-level international standards for the regulation of market participants that are in the business of dealing, making a market or intermediating transactions in OTC derivatives ("OTC derivative market intermediaries" or "DMIs")."11

\section{Growing and Getting International Advantage}

It is not new or unknown that going international, means getting competitive advantage for the services and products. The three main columns to be focused on this are:

1. Product leader

2. Operational excellence

3. Customer intimate ${ }^{12}$

All this claims for successful creation of customer-focused value proposition ${ }^{13}$, a cogent reason why the international customer should buy our products and services. Referring to Porter's analysis on the competitive advantage of the nations, the columns here above can be deployed in many variables weighting in different correlation to the economic growth of a country. We can analyze it in two points of view referring to the value proposition for the prospective customer; benefits or costs. In order to get advantage we need to maximize benefits or to reduce costs. The second is more limited and regarded to the better combination of the three main categories of the production factors, land, capital (function of funds and technology) and human capital. The better combination of these factors can induce an economy in terms of economy of scale or economy of abundance, based on large quantities of the supply in low costs. Considering the minimum and maximum potential demand of the market, due to the above mentioned combinations and macro forces present and acting in a certain state of nature of the economic and marketing environment, as well as its state in prosperity or recession, there are very discrete and often important insurmountable limitations, especially to economies similar to the Albanian one, to make possible economies of scale and abundance and to get competitive advantage being focused in costs reduction. The hard entrepreneurship to innovation, the lack of sufficient funds to investments, the low level of labor division and specialization, the limited resources necessary to support high yield industries, the low structure of capital, the harsh international competition on technology and innovation leadership and the hidden strategic alliances in the international and global market, make it difficult and further more impossible to our economy to be competitive cost oriented. The much distorted balance between exports and imports in our country in favor of the second provide proof and evidence on this limitation of our economy to gather competitive advantage internationally.

So the question arises "... How can we gather competitive advantage internationally with our brands of products and services, in order to extend exports compared to imports, improving the trade balance reducing trade deficit and giving space to more development and growth to the Albanian economy?"

\subsection{Price option approach}

This approach can be based in two main directions: factors' low cost and high production yields reducing costs per unit in products and services. Analyzing the first possibility we can find that Albania is not any longer the most or between attractive countries regarding the low costs of labor and other factors. There are other countries too equalizing or being

\footnotetext{
10 Professional Marketing Standards, Chartered Institute of Marketing, Berkshire UK, 2011

11 International Standards for Derivatives Market Intermediary Regulation, Final report, OICU-IOSCO, Technical Committee of International Organization of Security Commissions, 2012, pp. 1

12 Michael Treacy and Fred Wiersema, The Disciplines of Market Leaders, 1994

${ }_{13}$ Kotler and Keller, Marketing Management, 12e, 2006, pp. 310
} 
more attractive than we do regarding these costs in the area (Mediterranean and Balkan), but offering in the same time better possibilities to do and develop business (Monte Negro, FYROM, Serbia, Romania, Morocco, Tunisia, Turkey etc) ${ }^{14}$. We are not even a factor driven economy but already classified at the group of efficiency driven economies. Even considering the domestic market demand in Albania, our economy does not promise for economies of scale and low costs of products and services. While, compared to the Efficiency Enhancer Economies and the other two more advanced groups toward Innovation and Sophistication, we are far of being competitive focusing or being oriented in high production yields. We have low scores on efficiency and innovation closing up the bottom of the third group, that of efficiency enhancers. This also states the difficulty to reduce costs and increase competitiveness focusing on price option approach internationally. Of course, this is not an impossible approach, but the hardest one, with a low probability to be achieved.

The null hypothesis $\mathrm{H}_{0}$ - Reducing and managing production and transaction costs in order to increase and gather competitive advantage internationally growing economically by increasing revenues from international Albanian sales, has already shown to be a weakly yielding approach to the Albanian economic growth as we are not the most attractive cost oriented economy and products to the international market, both of products and services, as well to the FDI looking for better production conditions cost oriented. Some figures on 2011 showing the weak possibilities relying on this approach are shown in the tab. 1.

\begin{tabular}{|c|c|c|c|c|c|c|c|c|c|}
\hline & $\begin{array}{c}\text { Labor cost per } \\
\text { production unit } \\
\text { KPNj }{ }^{15}\end{array}$ & RUEC & $\begin{array}{c}\text { Inflation of } \\
\text { Import Prices } \\
(\%)\end{array}$ & $\begin{array}{c}\text { Index of Prod. } \\
\text { Prices / Costs } 17 \\
(\%)\end{array}$ & $\begin{array}{c}\text { Average structure } \\
\text { of capital } \\
\text { Ind/Agr }\end{array}$ & $\begin{array}{c}\text { Public } \\
\text { Debt cost } \\
(\%)\end{array}$ & $\begin{array}{c}\text { Inflation } \\
\text { Rate }{ }^{19} \\
(\%)\end{array}$ & $\begin{array}{c}\text { Interest Rate of } \\
\text { credit (ALL) } \\
(\%)^{20}\end{array}$ & $\begin{array}{c}\text { Education Cost per } \\
\text { hour of teaching } \\
(\text { Euro })^{21}\end{array}$ \\
\hline Score & $-3.9 \%$ & -4.7 & $>5^{22}$ & $2.2 / 3.3$ & $5</ 2.3$ & 4.3 & $3.0-4.5 \%$ & $10-15$ & $26-65$ \\
\hline
\end{tabular}

The scores in the table do not include the rate of informality of our economy of more than $12-15 \%$, which can provide a worse situation regarding cost and price factors impacting on the economic growth of Albania (having a negative average acceleration trend of almost $20 \%$ for the last four years), and especially showing for a weakening competitive advantage of our economy in the international market and on the attraction of FDI. There are not included in the above mentioned indicators in the table 1 other important facts and variables like the price of the land and the problems on private property on the land Albania is facing since 1992 till nowadays, the price of technology per unit of GDP (which in part is shown as non attractive one referring to the low structure of capital), the cost of infrastructure on the economic freedom and the easiness to do business in Albania etc, whose weight in the international competitiveness of our products deepen the negative impact and reduces the chances and opportunities to gather advantage, being the most cost attractive country in the region.

\subsection{Non-price option approach}

At this reasoning end on the above matter, the non-price approach emerges to be the largest one in chances and opportunities for success. These variables (factors) are hardly depreciative and consumable, furthermore full of potentialities and variability, giving large spaces and different ways to move successfully in the international market. They relate to functionality, performance, durability, design, style, reliability, competence, responsibility, customer relations management, courtesy, D.O.C. (denomination of origin controlled), authenticity, as well as use of non-cost options of distribution related to cultural affinity, ethnicity, tolerance and accountability, etc.

The hypothesis I raise is:

$\mathrm{H}_{1}$ - Inducing our economy to be oriented in creating genuine Albanian products and services focusing in standards of quality, communication, courtesy, as well as Albanian immigrant enclaves, in order to facilitate and foster the entrance

\footnotetext{
14 WEF Global Competitiveness Index Report 2011-2012, Table 3, pp. 15-17, (Subindexes: Basic Requirements: 71, Efficiency Enhancers 82, Innovation and Sophistication factors 102)

${ }_{15}$ Report of monetary policy on the first trimester 2012, Bank of Albania, pp. 51. Graf. 41

${ }^{16}$ Rate of Use of Economic Capacities, Report of monetary policy on the first trimester 2012, Bank of Albania, pp. 55, Graf. 46

17 Report of monetary policy on the first trimester 2012, Bank of Albania, pp. 52, Graf. 42

${ }^{18}$ Averaged figures using two samples of businesses in industry production (137 firms) and agriculture production (50 agr. and 50 livestock farmers) at the Region of Elbasan

${ }^{19}$ Report of monetary policy on the first trimester 2012, Bank of Albania, pp. 23, Graf. 10.

20 Data averaged by different interest rates used by the second tier banks in Albania on 2011

21 Higher Education in Albania, Wages Categorization System in Albania, public sector (averaged)

22 January - February, Report of monetary policy on the first trimester 2012, Bank of Albania, pp. 53
} 
in the international market ensuring increased economic value added to our economy through increased exports regionally and internationally.

The hypothesis is a non price/cost one gathering the impact of all the image building and cultural factors as independent variables to measure the growth in exports and the reduce of the negative score in trade balance, directly impacting on the economic growth of Albania.

\section{Competing Genuinely and Building the House of Quality}

In this case it is important to understand what would the international customer prefer to benefit from products and services, what are the competition's supply characteristics in order to understand where to gain advantage finding a steady and high image position in the customers mind and heart, as well as which marketing channels to use in order to internationalize more naturally and faster possible. We must build competitive advantage building houses of quality in order to give the customers other reasons than costs and prices to use in their choice to consume. We have two large choices on this regard; producing products of high image and quality designed as a special offer for the international market respecting international standards, and second, improving and modifying the existing products respecting international market standards of consumption and the requests of the international customer on quality. All is concern with the development of products and services that are the best-in-class with superior benefits to the customer and easily identifiable to fulfillment of its preferences.

"This philosophy contrasts the concept of breakthrough product development which is primarily concerned with "first-in-class" products, i.e., superior products that define new market segments and have no precedence in the market"23.

We can use this model based on building the HOQ set of matrices completing the framework of all non-price variables comprising total quality of the product requiring the consumer consensus during the design of the product and considering the competitors presence and the possible gaps to be designed with their offers, in order to make it possible for the consumer to chose our product easily identifying it by the competitors offer.

As Evans and Lindsay on 1996 used in their model of QFD, the first matrix regard customer requirement planning matrix, analyzing and understanding the consumers' requirements on the product as a set of parts intended to maximize quality and benefits they could gather by our product or service. We can build this matrix passing through a number of steps:

1. Identifying potential customers abroad

2. Identifying their specific requirements on the products or service

3. Identify the mix of technical parts intended to fulfill costumer requirements

4. Identifying and screening consumption standards abroad binding or principally used to be respected

5. Identifying competitors in the sector

6. Branding the product or service ensuring their authenticity and genuineity

7. Deploying the best-of-class parts of the product or service to differentiate those to the costumer

8. Communicating the value proposition to the international costumer

Once concluding with the creation of the first matrix, and based on the results of our research according to the steps above, we can build other three matrices; the component requirements matrix in order to find the parts of the product to be deployed in order to increase the mix of benefits the costumer could gather from the product, the operations matrix establishing the production and manufacturing processes to be applied in order to guarantee the requirements on the products and their quality, and the quality control processes for each stage of the completion of our offer to the international customer.

The other two elements to complete the total quality are, first, the building of a high image related to the denomination of the origin of the products - made in Albania, and second, building the enclave of distribution and consumption abroad using the Albanian immigrant groups as ethnic groups of consumers and bidders for the genuine Albanian products and services, facilitating their entrance in the international market and fostering the dissemination of the Albanian gusto abroad based on their bi-citizenship and bi-cultural nature.

The approach can be quantified using mathematic models, even though hard to measure quantitatively all the above listed variables.

In this case we concentrate in optimization tools that help building the first two matrices of the $\mathrm{HOQ}$, identifying and

${ }^{23}$ G.L. Vairaktarakis, Optimization tools for design and marketing of new/improved products using the house of quality, Journal of Operations Management, V 17, 1999, pp 646. 
measuring customers' requirements and preferences, rating the competitors, identifying international consumption standards of quality and finding out the parts' mix to be deployed in order to fit the prospective international customer requirements being clearly and easily differentiated and distinguished by the competitors products and services.

We can use on this regard a mathematical function corrected with a binary variable conditioning representing experts' opinion on the process as a whole on the internationalization of the specific products and services as a test of success to the possible result of the mathematical function of quality.

Similar to Vairaktarakis on $1999^{24}$, we can assume as follow:

1. The market is identified

2. A segmentation procedure is undertaken

3. Target market segments are identified and chosen

4. The competitors in the market are identified

5. The products are authentically genuine Albanian, both in production and consumption gusto

6. There have been conducted customer surveys to collect their requirements on the products and their parts and characteristics

In order to build a mathematical function on the maximization of the internationalization of our products and services abroad, increasing sales based on non-price options, we build the first matrix of the HOQ defining some notations as follow:

For the HOQ1 chart:

$n$ : number of customer requirements on the products and services

req $i$ : the $i$ th customer requirement

$r$ : the customer's preference rating of reqi

$e_{j}$ : the $j$ th engineering characteristic of the product or service

$m$ : number of engineering characteristics $e_{j}$

$a_{i j}$ : the intensity with which $e_{j}$ affects req $q_{i}$, for $1 \leq i \leq n$ and $1 \leq j \leq m$

$w_{j}$ : the weight with which $e_{j}$ affects product performance

$k$ : the number of the non-price variables impacting costumer behavior

$X_{k}$ : the non-price variables impacting costumer behavior on our product and services taking values $0 \leq X \leq 1$

$\hat{Y}_{j}$ : the estimated combined effect in the customer preference on the product combination ' j' under the impact of $X$, for $I=1,2, \ldots k$

$C_{i j}$ : The cost of the ' $j$ '-th combination of the product mix under the requirements ' $i$ '

$P_{j}$ : the price accepted by the customer for the product under the combination of $e_{j}$ (under the estimated $\hat{Y}_{j}$ index of the customer preferences)

The intensity coefficients ' $a_{i j}$ ' represent the rigorousness of the product designers to meet the requirements of the customers through combinations of the engineering characteristics $e_{j}$, or different possibilities of combinations of the mix parts of the products to answer the reqi of the customers. We assume $a_{i j} \geq 0$. If $a_{i j}=0$ this shows for products designed in total darkness to the customer requirements, that means no correlation between req $q_{i}$ and $e_{j}$. ' $a_{i j}$ ' are the unit values of the matrix $\left\{\right.$ reqi; $\left.e_{j}\right\}$.

In our case the weights $w_{j}$ should be induced by the customer ratings ' $r$ ' on the importance of the reqi and the intensity coefficients $a_{i j}$. It can be expressed:

$$
w_{j}=\sum_{i=1}^{n} r_{i} a_{i j} \quad \text { for } j=1,2, \ldots, m
$$

The values of $r_{i}$ are previously measured under estimation related to answers directed to the people during operational stages with existing products 25 .

If $\mathrm{P}_{\mathrm{j}}\left(\mathrm{Y}_{\mathrm{j}}\right)$ is the price accepted by the customers for the product ' $\mathrm{j}$ ', or the combination ' $e_{j}$ ', then the condition to increase sales internationally based on the price created oriented in the market non-price option variables can be expressed as difference between the price and the production costs per unit:

$$
S=\operatorname{Max} \sum_{i=1}^{n} \sum_{j=1}^{m} w_{j}\left[P_{j}\left(\hat{Y}_{j}\right)-C_{i j}\right] Q_{j}
$$

If we assume that the customer may not choose at all our product, we can introduce the dummy variable $Z_{i j}$ that represents the choice or not of our product by the customer:

\footnotetext{
${ }^{24}$ G.L. Vairaktarakis, Optimization tools for design and marketing of new/improved products using the house of quality, Journal of Operations Management, V 17, 1999, pp. 648

${ }^{25}$ Table values based on historical data collected on several characteristics and the customer benefits related with, in older and similar products.
} 
$Z i j=\left\{\begin{array}{l}1, \text { if 'ej' is selected by the costumer to fulfil his 'reqi' } \\ 0,0 \text { otherwise }\end{array}\right.$

Under this assumption the increase in sales ' $S$ ' can be expressed as follow:

$$
S=\operatorname{Max} \sum_{i=1}^{n} \sum_{j=1}^{m} w_{j}\left[P_{j}\left(\hat{Y}_{j}\right)-C_{i j}\right] Z_{i j} Q_{i}
$$

Where $Q_{i}$ represents the quantity bought from the demand 'i', and $\hat{Y}_{j}$ represents the customer preference on the product under the impact of non-price factors in the market described here above $X_{I}$ and can be defined as follow:

$$
\hat{Y}_{\mathrm{j}}\left(X_{l}\right)=\alpha_{0}+\alpha_{1} X_{1}+\alpha_{2} X_{2}+\ldots . .+\alpha_{k} X_{k}+v
$$

We can add also the effect of the competitor's products and services, in order not to have just the consensus of the customers to design our offer, but to consider the advantage we have on our competitors too.

If the difference in perception is positive on the favor of our product, it says that the product or service designed by us, considering all the customer requirements and the non-price factors has passed the class, and can be considered a winner between the best-in-class offers of the competitors, otherwise, if negative, it means that we still have to improve the product in order to gather more attention and higher image by the customers. In this case we have considered the customers' consensus regarding the competitors' products and services too.

The application of the approach on the competitive advantage will be subject to another paper. It can be calculated for the neighbor and international markets, and with a stronger focus on the markets where the Albanian enclave of immigrants and ethnic minorities already exist. It is interesting to measure the effect of ethnicity in the international entrance of our genuine Albanian products, considering also their possible role as transnational bridges with bilateral affinity, international due to their international citizenship living in other countries than Albania, and the other side, being still Albanians and having strong ties with their home country, as well as sharing mostly the same culture and behavior in many aspects. The emergence and creation of enclave markets and marketing channels and the use of their ties with the international market, could be another set of non-price factors influencing the internationalization of the Albanian gusto and the increase in sales internationally. We assume too, that they face lower costs of international marketing and business than using traditional international marketing channels already existing in the international market. Adding here their social interests on being employed in more qualitative work and ranking possibly higher in the societies they live and work (actually residents), increases their interests in organizing ethnic enclaves and entrepreneurship there. They also can import/export in Albania the international standards in consumption and behavior, making it easier for our product and service designers to design offers with the same engineering standards for every characteristic, in order to fit better with the international consumer requirements.

\section{Methodology}

In this paper I have used the concept of the HOQ and the QFD, used earlier on 1972 by Mitsubishi's Kobe shipyard site, then by several companies on 1977-1986, improved on 1990 with the concept of the best-in-class by Akao, completed more by Evans and Lindsay on 1996, optimized in use by Vairaktarakis on 1999 with the concept of the House of Quality $(\mathrm{HOQ})$. By this methodology we can consider and measure the consumer consensus regarding their consumption requirements and their consensus on the advantage our product can gather in front of the competitors.

The model as presented here has some important modifications as it is more easy to be used by the marketing specialists and more operative integrating the engineering part of the product design and project, with the impact of the non-price factors in the level of performance of the product or service expressed through the price level due to the effect of this factors in the consumer preference. The impact of the non-price factors in the consumer preference is a simple multiple linear regression where the factors are tested on their importance with AIC backward induction method.

It is based on mathematical optimization models associated with stereotyped solutions on the engineering characteristics combinations due to a certain level of technology and e certain level of bargaining power of the international consumer according to the conditions and the level of the development of the specific international markets. The equations can be solved mathematically through optimization methods. Matrices are used too.

Data collected on the consumers and on the competitors or their networks are randomized and with representative population.

Regarding the rating on the customers' requirements importance, I suggest for practical reasons to be considered the expertise of the experts in international business and marketing. But, even longer way, it can be also part of the data collected randomized directly by the international customer by interview or questionnaires in the place.

It does not consider the asymmetry between consensus ratings by the consumers and their perceptual gaps due to 
different cultural characteristics.

\section{Findings and Recommendations}

Studying the problem by two point of views; the cost/price options and the non-price options, makes it more evident that Albanian products and services can internationalize more and in higher levels relying more on the second approach.

There are several alternatives to be identified and exploited to go international.

There are also three main directions we can rely in order to gather competitive advantage; product leader, operational excellent firm and customer intimate firm. Analyzing these three important columns we can easily find out that the impact of the non-price options is too much larger than the first one.

Respecting international standards on quality, security, hygiene, health, process and accountability can guarantee more competitive advantage for our products and services.

Using also, as non-price factors, the marketing performance indicators in order to internationalize more efficiently and faster too, are also prerogatives rising in front of the Albanian companies and economy as whole.

The use of the Albanian immigrants and ethnic enclaves, both as consumers and entrepreneurs, as a first step to going international with our "made in Albania" products and services, can be e ne challenge to be considered having present all the advantages this can offer, which are already explored in other ethnic minorities cases worldwide.

The last, which gives a complete meaning to the findings above, is that going international does not mean being the cheaper one, but different, diverse and variable, as well as with granted origin, that "made in Albania".

On the light of this study, I suggest that the Albanian government should find the ways to foster the internationalization of our products and services creating new spaces for business and designing new laws too.

Almost the same recommendation goes to the Albanian business to in order to consider other possibilities based on international standards, professionalism, originality, performance, culture, ethnicity etc to go international.

The above mentioned options can give breath to a new stage of growing of the Albanian economy.

\section{Abbreviations and Acronyms}

$\begin{array}{lll}\text { WTO } & - & \text { World Trade Organization } \\ \text { EU } & - & \text { European Union } \\ \text { SAA } & - & \text { Stabilization and Association Agreement } \\ \text { NA } & - & \text { Not Applicable } \\ \text { GDP } & - & \text { Gross Domestic Product } \\ \text { FDI } & - & \text { Foreign Direct Investments } \\ \text { OTC } & - & \text { Over The Counter } \\ \text { DMI } & - & \text { Derivative Market Intermediary } \\ \text { RUEC } & - & \text { Rate of Use of Economic Capacities } \\ \text { ALL } & - & \text { Albanian Lek } \\ \text { D.O.C. } & - & \text { Denomination of Origin Controlled } \\ \text { HOQ } & - & \text { House Of Quality } \\ \text { QFD } & - & \text { Quality Function Deployment }\end{array}$

\section{References}

John Naisbit, Mind Set: Reset Your Thinking and See the Future, 2006

Philip Kotler and Kevin Lane Keller, Marketing Management, 12e, 2006

Haydar Bas, National Economic Model, 2005

David Frey, The Small Business Marketing Bible, 2003

Gabriel Moens and Peter Gillies, International Trade and Business: Law, Policy and Ethics, 1998

Michael Treacy and Fred Wiersema, The Disciplines of Market Leaders, 1994

Michael Porter, Competitive Advantage of Nations, 1990

International Standards for Derivatives Market Intermediary Regulation, Final report, OICU-IOSCO, Technical Committee of International Organization of Security Commissions, 2012

WEF Global Competitiveness Index Report 2011-2012

Report of monetary policy on the first trimester 2012, Bank of Albania

Reducing Trade Barriers for Environmental Goods and Services in APEC Economies, Mapping Exercise for Energy Efficient Products, 
ICF international, Prosper center, Beijing, China, Final Report 2011

Professional Marketing Standards, Chartered Institute of Marketing, Berkshire UK, 2011

Qiang Ding, Michele EM. Akoorie and Kathrin Pavlovich, Going International,; The Experience of Chinese Companies, International Business Research, Vol. 2, No. 2, April 2009

Xiao Wang, Study on the "Going-out" Business Mode of Chinese Enterprise, International Journal of Business Management, Canadian Center of Science and Education, Vol. 4, No. 1, January 2009

Gupta and Saghaian, An Institutional Framework for Meeting International Food-Safety Market Standards, Journal of Food Distribution Research 39(1), March 2008

Neva Godwin, Julie A. Nelson, Frank Ackerman and Thomas Weisskopf, Consumption and the Consumer Society, Microeconomics in Context, M.E. Sharpe 2008

Irma Patala, Services Going Global - KIBS and Trade, FINPRO 2008

Hirotaka Matsumoto, The Internationalization of Sushi, Kikkoman Food culture Seminar, 2007

James L. Seali Jr. and Anita Regmi, Modeling International Consumption Patterns, Review of Income and Wealth, Series 52, No. 4, Dec. 2006

Veerapong Malai and Mark Speece, Cultural Impact on the Relationship among Perceived Service Quality, Brand Name Value, and Customer Loyalty, Journal of International Consumer Marketing, Vol.17(4) 2005

Ramkishen S. Rajan, FDI, Trade and Internationalization of Production in the Asia-Pacific Region: Issues and Policy Conundrums, AsiaPacific Trade and Investment Review, 2005

Mark J. Gehlhar, Anita Regmi, Spiro Stefanou and Barry Zoumas, Brand Leadership and Product Innovation as Firm Strategies in Global Food Markets, International Food and Agribusiness Management Association, 15th Annual World Food and Agribusiness Forum: "Re-inventing the Food Chain: New Products, Consumers, and Markets" June 25-28, 2005

International Standards: Strengthening Surveillance, Domestic Institutions, and International Markets, World Bank and International Monetary Fund Research, March 2003

Vrinda Kadiyali, K. Sudhhir and Vithala R. Rao, Structural analysis of competitive behavior: New Empirical Industrial Organization methods in marketing, International Journal of Research in Marketing, 2001

Child, J. \& Yan, Y., National and transnational effects in international business: Indications from Sino-foreign joint ventures, Management International Review, 41, pp. 53-75, 2001

G.L. Vairaktarakis, Optimization tools for design and marketing of new/improved products using the house of quality, Journal of Operations Management, V 17, 1999

Chris Lewis and Sara Stubbs, National expansion of British regional brands: parallels with internationalization, Journal of Product \& Brand Management, Vol. 8, No. 5, pp. 369-386, 1999

Consumer Charter for Global Business, Consumers International, London, Oct. 1997 